\title{
Health Considerations in Regulation and Taxation of Electronic Cigarettes
}

\author{
Arch G. Mainous III, PhD, Rebecca J. Tanner, MS, Ryan W. Mainous, and \\ Jeffery Talbert, $P h D$
}

The use of electronic cigarettes (e-cigarettes) is experiencing unprecedented growth. This can be contrasted to the use of conventional cigarettes which showed a decrease among adults with the current smoker prevalence dropping from $20.9 \%$ in 2005 to $17.8 \%$ in 2013 . There is some data that e-cigarettes are attracting both former smokers and never smokers, and in particular, young people as users. Currently most states do not tax e-cigarettes. Taxation and regulation may have a similar overall goal of decreasing smoking but regulation tends to focus reduced availability of products. In terms of tobacco control, taxation focuses on the demand side of the equation. Taxation is a distinct strategy from regulation and has been shown to decrease new adopters of conventional cigarettes. A variety of potential taxation strategies can be considered by policymakers based on different assumptions about e-cigarettes and their utility, ranging from untaxed to taxation at moderate levels compared to conventional cigarettes to taxation equal to conventional cigarettes. Until more evidence for the benefits of e-cigarettes is presented, it seems prudent to view them as a potentially harmful and addictive product that ought to be regulated and taxed in an equivalent manner to conventional cigarettes. ( $\mathrm{J}$ Am Board Fam Med 2015;28:802-806.)

Keywords: Electronic Cigarettes, Health Policy, Smoking, Taxation

The use of electronic cigarettes (e-cigarettes) is growing at an unprecedented rate. E-cigarettes are battery-powered devices that convert a solution of nicotine and other chemicals into a vapor that can be inhaled. They entered the market in the United States in 2007 and have gained a substantial market increase. ${ }^{1-3}$ This can be contrasted with the use of conventional cigarettes, which decreased among adults; the current smoker prevalence dropped from $20.9 \%$ in 2005 to $17.8 \%$ in $2013 .{ }^{4}$ Recent

This article was externally peer reviewed.

Submitted 31 March 2015; revised 11 June 2015; accepted 15 June 2015.

From the Department of Health Services Research, Management, and Policy, University of Florida, Gainesville (AGM, RJT); the Department of Community Health and Family Medicine, University of Florida, Gainesville (AGM); and the Institute for Pharmaceutical Outcomes and Policy, University of Kentucky, Lexington (RWM, JT).

Funding: none.

Conflict of interest: none declared.

Corresponding author: Arch G. Mainous, PhD, Department of Health Services Research, Management and Policy, University of Florida, Health Sciences Center, PO Box 100195, Gainesville, FL 32610 (E-mail: arch.mainous@phhp. ufl.edu). data indicated that e-cigarette sales more than doubled between 2012 and 2013, from \$273.6 million to $\$ 636.2$ million. $^{5}$

There are some data that e-cigarettes are attracting both former smokers and never smokers. ${ }^{1-6}$ In fact, one estimate suggests that nearly one third $(32.5 \%)$ of current e-cigarette users are never or former smokers. ${ }^{1}$ The downstream implications for illness from e-cigarettes are unknown, but because e-cigarettes are nicotine delivery devices, there is some concern over nicotine addiction, particularly among new users. ${ }^{2,7,8}$

Some authors have argued that e-cigarettes should be perceived as a healthy alternative to conventional cigarettes for cigarette smokers and as a smoking cessation device, although those benefits have yet to be definitively demonstrated. ${ }^{8,9}$ In fact, a recent systematic review concluded that no firm conclusions can be drawn about the safety of e-cigarettes but that they should not be considered harmless. ${ }^{10}$

From the perspective of a family physician and tobacco control or smoking cessation among his or 
her patients, the status of e-cigarettes can be quite vexing. One survey of family physicians in North Carolina found that more than two thirds of respondents considered e-cigarettes to be a helpful aid for smoking cessation, and $35 \%$ recommended them to their patients. ${ }^{11}$ Regardless of claims of e-cigarettes as smoking cessation tools and corresponding calls to regulate e-cigarettes, the US Food and Drug Administration (FDA) attempted and failed to regulate the products as drug delivery devices. ${ }^{9,12,13}$ In 2010, an e-cigarette maker sued the FDA to prevent e-cigarettes from being regulated as a drug or therapeutic device. The US Court of Appeals for the District of Columbia Circuit determined that e-cigarettes could be regulated as tobacco products but would not be regulated as drugs or devices, with the condition that they are not marketed for therapeutic purposes. ${ }^{14}$ The FDA continues to monitor compliance with this proviso and, in line with the condition, has issued warning letters to several distributors for claiming their products can successfully help their users to quit smoking. ${ }^{15}$ Only e-cigarettes that are marketed for therapeutic purposes are currently regulated by the FDA Center for Drug Evaluation and Research. ${ }^{16}$

Ongoing debates focus on whether e-cigarettes should be considered tobacco products. The FDA issued a proposed rule that would extend the agency's tobacco authority to cover additional products that meet the legal definition of a tobacco product, such as e-cigarettes, but as it stands e-cigarettes are not regulated as tobacco. ${ }^{16}$

Although a number of states, including Minnesota and North Carolina, have voted to legally define e-cigarettes as tobacco, other states do not define e-cigarettes as tobacco, and still others are still debating their status in this changing landscape. ${ }^{17,18}$ Kentucky does not consider e-cigarettes as a tobacco product. ${ }^{19}$ In June 2015 the California State Senate approved a bill to treat e-cigarettes as tobacco products. ${ }^{20}$ As of this writing, the measure has yet to pass the California General Assembly. At the same time, the FDA is still debating e-cigarettes as tobacco. Despite the lack of clarity regarding e-cigarettes as tobacco products, 12 states considered taxing ecigarettes in 2014. None of the proposals passed. ${ }^{21}$ The revenue on state taxes of conventional cigarettes typically goes into a general fund, and that money is not designated for health care, but others have argued that the money could be useful as a funder for health care programs. $^{22,23}$

Should e-cigarettes be taxed? If they are to be taxed, at what rate? What is the goal of taxation? Debates about the goal of taxation are swirling in state legislatures, with a variety of goals in mind. Taxation has been a successful strategy to decrease demand and control tobacco use. ${ }^{23}$ Taxation and regulation may have a similar overall goal of decreasing smoking, but regulation, which uses strategies such as minimum purchase age and restrictions on areas of sale, may have intermediate goals such as standardization and reduced availability of products. However, taxation is a distinct strategy from regulation. In terms of tobacco control, taxation focuses on the demand side of the equation, whereas regulation focuses on the supply side. Similarly, taxation has the advantage of generating public revenue. In Oregon, the chairman of the House Revenue Committee remarked that the state should look at taxing e-cigarettes, hitting on both goals by saying, "I am always interested in keeping drugs away from kids and generating some money." 24 We outline several potential taxation strategies that may be considered by policymakers based on different assumptions about e-cigarettes and their utility.

\section{Untaxed}

The first strategy that could be used by policymakers is to leave e-cigarettes not subject to cigarette taxes. The assumption would be that e-cigarettes are a safe alternative to conventional cigarettes. ${ }^{18}$ One commentator called e-cigarettes "a public health revolution" and suggests that the FDA should allow e-cigarette makers to tell smokers of the benefits of switching to e-cigarettes. ${ }^{25}$ Taxation of e-cigarettes would decrease the attractiveness of e-cigarettes compared with conventional cigarettes, thereby not encouraging smokers to switch to the healthier alternative. The evidence regarding the health benefits of e-cigarettes in comparison to conventional cigarettes is not clear, and so making e-cigarettes economically attractive by being untaxed may generate public revenue, but it may not achieve the goal of being a safe alternative to conventional cigarettes. ${ }^{9}$ Perhaps the more important unanswered question is whether there is a benefit or harm from e-cigarettes that would be experi- 
enced when compared with never using a tobacco product - that question should be driving any tax advantage to e-cigarettes.

\section{E-cigarettes Taxed at a Moderate Level Compared with Conventional Cigarettes}

A second option is to tax e-cigarettes at more moderate levels than conventional cigarettes, with an e-cigarette tax that is not linked to cigarette taxes, as North Carolina has done. Assuming that e-cigarettes are a healthier alternative to regular cigarettes, discouraging movement to e-cigarettes via high taxes on e-cigarettes would not be a useful strategy for the goal of either actively or passively encouraging the substitution of e-cigarettes for conventional cigarettes. Taxing e-cigarettes at more moderate levels would not generate the same tax revenues for states and the federal government as taxing at the same rate as conventional cigarettes, but it would still generate some revenue. This strategy would fit with the assumption that e-cigarettes should be placed in the marketplace as a more financially attractive option compared with conventional cigarettes, thereby encouraging e-cigarettes as a substitute for cigarettes.

\section{E-cigarettes Taxed as Conventional Cigarettes}

One thing is clear about e-cigarettes and health: e-cigarettes are a nicotine delivery system and thus have the opportunity to create new nicotine addicts. ${ }^{26}$ One estimate suggested that essentially a third of e-cigarette users were former or never smokers. ${ }^{1}$ Evidence suggests that the pattern of e-cigarette use among young people differs from that among adults. ${ }^{2}$ Among young people, e-cigarette use was not used as a substitute for cigarettes among existing smokers, but, rather, most new ecigarette users had never used cigarettes. Many of the flavors (eg, peach, vanilla, cherry) have the potential of making e-cigarettes more appealing to nicotine-naïve individuals who are not already addicted. This suggests that e-cigarettes are not simply presumed to be healthy alternatives to conventional cigarettes for current smokers, but rather a strategy for recruiting new users. This position has been forwarded in North Dakota as the state debates taxing e-cigarettes. One North Dakota state representative said, "I do not know how we can separate the idea of discussing e-cigarettes and then we're going to talk about the taxing of tobacco when it is clearly a tobacco product." 27

A third option is to subject e-cigarettes to cigarette taxes. This option suggests that e-cigarettes are not smoking cessation tools, as contended by a variety of manufacturers in the e-cigarette industry, and that they create more nicotine addicts and therefore should not be rewarded economically in the marketplace. Taxing e-cigarettes at the rate of conventional cigarettes would clearly initially create substantially more revenue, but it would also likely decrease the increasing demand for e-cigarettes. This would decrease future tax revenues unless e-cigarettes created more new users rather than conventional cigarette smokers switching to e-cigarettes. Cigarette taxes are commonly applied to stop individuals from smoking because tobacco use is price sensitive. In a study of youth in 38 countries, the price elasticity of smoking conventional cigarettes is -1.5 for a sample that contains both high-income and low- and middle-income countries, indicating a $15 \%$ decrease in demand for every $10 \%$ increase in price. ${ }^{28}$ Constraining the sample to only low- and middle-income countries, the study found a total price elasticity of -2.2 , suggesting that smoking among youths in low-income countries is even more responsive to cigarette price changes. Huang et $\mathrm{al}^{29}$ estimate the elasticity for reusable e-cigarettes to be -1.9 , indicating a $19 \%$ decrease in demand for every $10 \%$ increase in price. It could be argued that e-cigarettes are similar to other nicotine replacement products that do not require a prescription (eg, gum, patch) and should be conceptualized as such rather than like conventional cigarettes. However, other nicotine replacement strategies tend not to attract individuals who have not been smokers, so e-cigarettes seem to be qualitatively different.

\section{Taxation Rather Than Regulation?}

Tobacco control has historically relied on both regulation and taxation. Regulation and taxation should work in concert and should not be an either/or position in devising policy. Laws related to regulation tend to focus on the supply side of the equation by controlling access, whereas tax policy focuses on the demand side through price elasticity. A variety of medical organizations, including the 
American Medical Association and the American Academy of Family Physicians, have policy positions favoring the regulation of electronic cigarettes. ${ }^{30-33}$ Unfortunately, the definitional problems that have dogged discussion about taxing e-cigarettes also affect the regulation of e-cigarettes. For example, in a recent legislative debate regarding the regulation of e-cigarettes in Montana, a legislator said about the argument against conventional cigarettes by advocates of e-cigarettes: "They are trying to muddy the issue by saying 'tobacco and nicotine,' but people do not understand they are one [and] the same." ${ }^{\text {4 }}$ Moreover, views on regulation and taxation are based on the underlying assumptions discussed above about the utility of e-cigarettes (eg, smoking cessation tool, healthier alternative to conventional cigarettes, mechanism for new nicotine addicts) and, correspondingly, whether they should be encouraged or discouraged in the marketplace.

\section{Conclusion and Recommendations}

In their current untaxed position, e-cigarettes are a financially attractive alternative to conventional cigarettes. Based on the current evidence about health and the contention by several e-cigarette manufacturers that they not be seen as a smoking cessation treatment, it seems that leaving e-cigarettes in a financially attractive position, particularly for never smokers, is not warranted. Taxation at rates consistent with conventional cigarettes would provide public revenues but would also likely decrease demand among former or never smokers. This would decrease the creation of new nicotine addicts. Taxation should be implemented with regulatory policies to affect both supply and demand for e-cigarettes. Until more evidence for the benefits of e-cigarettes is presented, it seems prudent to view them as a potentially harmful and addictive product that ought to be regulated and taxed in an manner equivalent to conventional cigarettes.

\section{References}

1. McMillen RC. Gottlieb MA, Shafer RM, Winickoff JP, Klein JD. Trends in cigarette use among US adults: use is increasing in both smokers and nonsmokers. Nicotine Tob Res 2015;17:1195-202.

2. Carroll Chapman SL, Wu LT. E-cigarette prevalence and correlates of use among adolescents versus adults: a review and comparison. J Psychiatr Res 2014;54:43-54.
3. King BA, Patel R, Nguyen KH, Dube SR. Trends in awareness and use of electronic cigarettes among U.S. adults, 2010-2013. Nicotine Tob Res 2015;17: 219-27.

4. Kandra KL, Ranney LM, Lee JG, Goldstein AO. Physicians' attitudes and use of e-cigarettes as cessation devices, North Carolina, 2013. PLoS One. 2014;9:e103462.

5. Giovenco DP, Hammond D, Corey CG, Ambrose $\mathrm{BK}$, Delnevo CD. E-cigarette market trends in traditional US retail channels, 2012-2013. Nicotine Tob Res 2015;17:1279-83.

6. Giovenco DP, Lewis MJ, Delnevo CD. Factors associated with e-cigarette use: a national population survey of current and former smokers. Am J Prev Med 2014;47:476-80.

7. Wills TA, Knight R, Williams RJ, Pagano I, Sargent JD. Risk factors for exclusive e-cigarette use and dual e-cigarette use and tobacco use in adolescents. Pediatrics 2015;135:e43-51.

8. Drew AM, Peters GL, Danis PG. Electronic cigarettes: cautions and concerns. Am Fam Physician 2014;90:282-4.

9. Brandon TH, Goniewicz ML, Hanna NH, et al. Electronic nicotine delivery systems: a policy statement from the American Association for Cancer Research and the American Society of Clinical Oncology. Clin Cancer Res 2015;21:514-25.

10. Pisinger C, Døssing M. A systematic review of health effects of electronic cigarettes. Prev Med 2014;69: 248-60.

11. Jamal A, Agaku IT, O'Connor E, King BA, Kenemer KB, Neff L. Current cigarette smoking among adults-United States, 2005-2013. MMWR Morb Mortal Wkly Rep 2014;63:1108-12.

12. Cobb NK, Abrams DB. E-cigarette or drug delivery device? Regulating novel nicotine products. N Engl J Med 2011;365:193-5.

13. Franck C, Budlovsky T, Windle SB, Filion KB, Eisenberg MJ. Electronic cigarettes in North America: history, use, and implications for smoking cessation. Circulation 2014;129:1945-52.

14. US Food and Drug Administration. Stakeholder letter: regulation of e-cigarettes and other tobacco products. April 25, 2011. Available from: http://www. fda.gov/newsevents/publichealthfocus/ucm 252360 . htm. Accessed March 30, 2015.

15. US Food and Drug Administration. FDA acts against 5 electronic cigarette distributors [Press release]. September 9, 2010. Available from: http://www. fda.gov/NewsEvents/Newsroom/PressAnnouncements/ 2010/ucm225224.htm. Accessed March 30, 2015.

16. US Food and Drug Administration. Electronic cigarettes (e-cigarettes). Available from: http://www. fda.gov/NewsEvents/PublicHealthFocus/ucm172906. htm. Accessed June 10, 2015.

17. North Carolina statutes GS 14-313. Youth access to tobacco products, tobacco-derived products, vapor 
products, and cigarette wrapping papers. Available from: http://www.ncga.state.nc.us/enactedlegislation/ statutes/html/bysection/chapter_14/gs_14-313.html. Accessed June 10, 2015.

18. Minnesota Department of Revenue. E-cigarettes. Minnesota statutes, section 297F.01, subdivision 19. Available from: http://www.revenue.state.mn.us/ businesses/tobacco/Pages/e-Cig.aspx. Accessed June $10,2015$.

19. Kentucky Department of Revenue. Tobacco taxes. Available from: http://revenue.ky.gov/business/ Tobaccotax.htm. Accessed June 10, 2015.

20. McGreevy P. California Senate votes to restrict ecigarettes as tobacco products. Los Angeles Times, June 2, 2015. Available from: http://www.latimes.com/ local/political/la-me-pc-california-senate-votes-torestrict-ecigarettes-like-tobacco-products-20150602story.html. Accessed June 10, 2015.

21. Povich ES. States look to tax e-cigarettes. Government Executive, January 23, 2015. Available from: http://www.govexec.com/state-local/2015/01/states-ecigarette-taxes/103584/. Accessed January 26, 2015.

22. Munzer A; ATS Tobacco Action Committee. Raising tobacco taxes: a timely prescription for U.S. public and fiscal health. Ann Am Thorac Soc 2013; 10:253-4.

23. Chaloupka FJ, Yurekli A, Fong GT. Tobacco taxes as a tobacco control strategy. Tob Control 2012;21: 172-80.

24. Cooper, JJ. Oregon lawmakers debate e-cigarette taxes. Associated Press, September 18, 2013. Available from: http://finance.yahoo.com/news/oregonlawmakers-debate-e-cigarette-002007452.html. Accessed March 30, 2015.

25. Satel SL. Will the F.D.A. kill off e-cigs? New York Times, January 18, 2015. Available from: http:// www.nytimes.com/2015/01/19/opinion/will-the-fda-killoff-e-cigs.html?hp\&action $=$ click\&pgtype $=$ Homepage \&module $=\mathrm{c}$-column-top-span-region $\&$ region $=\mathrm{c}$ column-top-span-region \&W'T.nav=c-column-topspan-region\&_r=1. Accessed January 26, 2015.
26. Pisinger $\mathrm{C}$. Why public health people are more worried than excited over e-cigarettes. BMC Med 2014;12:226.

27. Cigarette tax and e cigarettes debated in ND legislature. KX News, February 14, 2015. Available from: http://www.wday.com/news/north-dakota/3679119cigarette-tax-and-e-cigarettes-debated-nd-legislature. Accessed March 30, 2015.

28. Nikaj S, Chaloupka FJ. The effect of prices on cigarette use among youths in the global youth tobacco survey. Nicotine Tob Res 2014;16(Suppl 1):S16-23.

29. Huang J, Tauras J, Chaloupka FJ. The impact of price and tobacco control policies on the demand for electronic nicotine delivery systems. Tob Control 2014;23(Suppl 3):iii41-7.

30. American Medical Association. AMA supports further regulation of electronic cigarettes to protect youth [Press release]. November 10, 2014. Available from: http://www.ama-assn.org/ama/pub/news/news/ 2014/2014-11-10-further-regulation-electroniccigarettes-protect-youth.page. Accessed January 26, 2015.

31. American Medical Association. AMA strengthens position on regulation of electronic cigarettes [Press release]. June 10, 2014. Available from: http:// www.ama-assn.org/ama/pub/news/news/2014/201406-10-regulating-electronic-cigarettes.page. Accessed January 26, 2015.

32. American Medical Association. AMA supports FDA's efforts to regulate e-cigarettes, additional tobacco products [Press release]. April 24, 2014. Available from: http://www.ama-assn.org/ama/pub/news/ news/2014/2014-04-24-ama-supports-fda-regulatee-cigarettes.page. Accessed January 26, 2015.

33. American Academy of Family Physicians. Electronic cigarettes. Available from: http://www.aafp.org/ about/policies/all/e-cigarettes.html. Accessed March $30,2015$.

34. Noon A. E-cigarettes up for debate at Montana Legislature. Associated Press, January 19, 2015. Available from: http://finance.yahoo.com/news/ecigarettes-debate-montana-legislature-213603515. html. Accessed March 30, 2015. 